\title{
PENGARUH BIMBINGAN KELOMPOK TERHADAP PENINGKATAN KOMUNIKASI INTERPERSONAL SISWA KELAS IX SMP NEGERI 3 BINJAI TAHUN PELAJARAN 2017-2018
}

\author{
M. Dian Wahyudi
}

STKIP Budidaya Binjai

\begin{abstract}
Abstrak
Keterampilan komunikasi interpersonal pada siswa ini menjadi sangat penting karena dalam bergaul dengan teman sebayanya, siswa seringkali dihadapkan dengan hal-hal yang membuatnya harus mampu menyatakan pendapat pribadinya tanpa disertai emosi, marah atau sikap kasar, bahkan siswa harus bisa mencoba menetralisasi keadaan apabila terjadi suatu konflik. Layanan bimbingan kelompok diperkirakan sangat tepat digunakan sebagai salah satu bentuk layanan bimbingan dan konseling untuk diberikan kepada siswa yang memiliki prilaku komunikasi interpersonal yang masih rendah, baik di rumah, sekolah maupun lingkungan masyarakat. Selain itu kelima aspek efektifitas prilaku komunikasi interpersonal yang meliputi keterbukaan, rasa positif, empati, dukungan, dan kesetaraan. Terdapat dalam kegiatan layanan bimbingan kelompok, bukan pada layanan bimbingan konseling lainnya. Sehingga diharapkan secara optimal siswa dapat mengalami perubahan dan mencapai peningkatan yang positif setelah mengikuti kegiatan bimbingan kelompok. Hasil penelitian ini menunjukkan bahwa pada tes komunikasi interpersonal diperoleh nilai rata-rata siswa sebesar 61,8 dan untuk tes bimbingan kelompok diperoleh nilai ratarata sebesar 78,18.untuk standar deviasi variabel x diperoleh nilai 8,5 dan untuk standar deviasi variabel y diperoleh nilai 7,5 menyatakan bahwa data yang diteliti bersifat normal dan perolehan data untuk homogenitas data menunjukkan bahwa data yang diteliti bersifat homogen. Untuk hasil $r_{\text {hitung }}=0,35$ dengan menggunakan taraf $5 \%$ maka diperoleh nilai $r_{\text {tabel }}=0,30$ dengan sampel 40 orang siswa. Kriteria pengujian adalah jika $\mathrm{r}_{\text {hitung }}>$ rtabel maka hipotesis diterima, berdasarkan kriteria tersebut, 0,35 >0,30 sehingga ada pengaruh bimbingan kelompok terhadap komunikasi interpersonal siswa kelas IX SMP Negeri 3 Binjai tahun pelajaran 2017/2018.
\end{abstract}

Kata Kunci : Bimbingan Kelompok dan Komunikasi Interpersonal

\section{PENDAHULUAN}

Manusia adalah makhluk sosial yang senantiasa ingin berhubungan dengan manusia lainnya, hubungan dengan manusia lain tidak lepas dari rasa ingin tahu tentang lingkungan sekitarnya. Dalam rangka mengetahui gejala di lingkungannya ini menuntut manusia untuk berkomunikasi.
Dalam hidup bermasyarakat, seseorang akan terisolasi jika tidak pernah berkomunikasi dengan orang lain. Keterisolasian ini dikhawatirkan dapat menimbulkan permasalahan yang kompleks.

Di lingkungan Sekolah tempat siswa berinteraksi, siswa sebagai bagian dari masyarakat dituntut dapat berkomunikasi 
dengan orang lain. Lingkungan yang dimaksud adalah sekolah. Karena hampir sebagian waktu siswa, banyak digunakan untuk berinteraksi di sekolah. Tugas siswa di sekolah yaitu belajar, dengan belajar siswa akan memperoleh perubahan yang positif dan dapat berkembang secara optimal serta siap melaksanakan peranannya dimasa yang akan datang.

Di UU RI No 20 Tahun 2003 tentang Sistem Pendidikan Nasional pada Pasal 3 menjelaskan bahwa "pendidikan nasional berfungsi mengembangkan kemampuan dan membentuk manusia Indonesia yang bermartabat dalam rangka mencerdaskan kehidupan bangsa", bertujuan untuk berkembangnya potensi peserta didik agar menjadi manusia yang beriman dan bertaqwa kepada Tuhan Yang Maha Esa, berakhlak mulia, sehat, berilmu, cakap, kreatif, mandiri dan menjadi warga negara yang demokratis serta bertanggung jawab. Bimbingan konseling membantu siswa meraih pengembangan diri yang optimal sesuai dengan tahap perkembangan dan tuntutan lingkungan yang positif.

Sugiyo
bahwa“Komunikasi
$\begin{aligned} & \text { mengemukakan } \\ & \text { interpersonal }\end{aligned}$
mempunyai dampak yang cukup besar bagi
kehidupan siswa. Dengan komunikasi
interpersonal siswa akan dapat
mengembangkan kepribadiannya, dapat
menyesuaikan diri dan akhirnya dapat
mengaktualisasikan dirinya dalam
lingkungannya". Keterampilan komunikasi
interpersonal pada siswa ini menjadi sangat
penting karena dalam bergaul dengan
teman sebayanya, siswa seringkali
dihadapkan dengan hal-hal yang
membuatnya harus mampu menyatakan
pendapat pribadinya tanpa disertai emosi,

marah atau sikap kasar, bahkan siswa harus bisa mencoba menetralisasi keadaan apabila terjadi suatu konflik.

Perkembangan remaja terjadi dalam konteks sosial yang meliputi keluarga, kelompok teman sebaya dan masyarakat tempat siswa itu tinggal. Maka dalam proses perkembangannya remaja akan selalu bersinggungan dengan situasi-situasi sosial yang tentu saja mengharuskan remaja untuk melakukan penyesuaian diri, dengan melakukan penyesuaian diri remaja dapat mengenal, memahami dan menerima dirinya sendiri serta lingkungan.

Peneliti melakukan Survey awal di SMP Negeri 3 Binjai peneliti menemukan masalah kesulitan siswa dalam menyesuaikan diri, agresivitas, mencari rasa aman pada berbagai bentuk mekanisme pertahanan diri (seperti rasionalisasi, proyeksi, egosentris, dan sebagainya), melanggar tata tertib, menentang guru, tidak melaksanakan tugas sekolah, mengisolasi diri dan sulit bekerja sama dalam situasi kelompok.

Layanan bimbingan kelompok dalam Pendidikan diperkirakan sangat tepat digunakan sebagai salah satu bentuk layanan bimbingan untuk diberikan kepada siswa yang memiliki perilaku komunikasi interpersonal yang masih rendah, baik di rumah, sekolah maupun lingkungan masyarakat. Selain itu kelima aspek efektifitas perilaku komunikasi interpersonal yang meliputi keterbukaan, rasa positif, empati, dukungan dan kesetaraan. Terdapat dalam kegiatan layanan bimbingan kelompok, bukan pada layanan bimbingan konseling lainnya. Sehingga diharapkan secara optimal siswa 
dapat mengalami perubahan dan mencapai peningkatan yang positif setelah mengikuti kegiatan bimbingan kelompok.

Siswa yang mengikuti kegiatan bimbingan kelompok dapat secara langsung berlatih menciptakan dinamika kelompok, yakni berlatih berbicara, menanggapi, mendengarkan dan bertenggang rasa dalam suasana kelompok. Kegiatan ini merupakan tempat perkembanagan diri dalam rangka belajar berkomunikasi secara positif dan efektif dalam kelompok kecil. Dari kegiatan tersebut siswa dapat menerapkan ke dalam kehidupan sosial masyarakat yang sesungguhnya.

\section{METODOLOGI PENELITIAN}

\section{Metode Penelitian}

Adapun metode penelitian yang digunakan dalam penelitian ini adalah penelitian eksperimen atau percobaan (eksperimental research) dengan cara memberikan perlakuan layanan bimbingan kelompok kepada kelompok eksperimen.

Variabel bebas dan variabel terikat dalam penelitian ini dapat digambarkan sebagai

berikut :

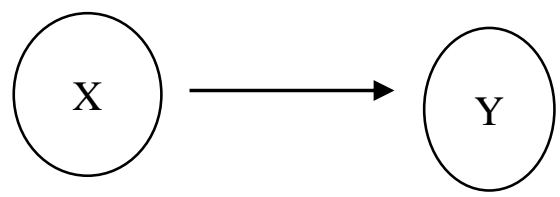

Gambar 1.Hubungan bimbingan kelompok dan komunikasi interpersonal siswa

Keterangan :

Kelompok

$$
\mathrm{X}=\text { Pengaruh Bimbingan }
$$

$$
\mathrm{Y}=\text { Peningkatan Komunikasi }
$$

Interpersonal
Variabel X mempengaruhi variabel Y. Layanan bimbingan kelompok sebagai variabel bebas $(\mathrm{X})$ mempengaruhi komunikasi interpersonal sebagai variabel terikat ( Y ).

\section{Tempat dan Waktu}

Tempat Penelitian ini dilakukan di SMP Negeri 3 Binjai yang terletak di Jl. Soekarno Hatta No.12 Binjai. Waktu penelitian ini dilakukan pada semester ganjil dari Bulan September s/d November Tahun Ajaran 2017 - 2018.

\section{Populasi dan Sampel Penelitian}

\section{Populasi}

Menurut Hermawan Warsito bahwa "Populasi adalah keseluruhan penelitian yang dapat terdiri dari manusia, benda, tumbuh-tumbuhan, gejala, nilai tes atau peristiwa, sebagai sumber data yang memiliki karakteristik tertentu dalam suatu penelitian".

Berdasarkan pendapat di atas maka populasi penelitian ini dibatasi hanya siswa yang duduk di kelas IX SMP Negeri 3 Binjai Tahun Pelajaran 2017/2018 sebanyak 405 orang yang terdiri dari sembilan kelas.

Tabel. Populasi Penelitian

\begin{tabular}{ccc}
\hline No & Kelas & Jumlah Siswa \\
\hline 1. & IX- $^{-}$ & 40 \\
\hline 2. & IX- $^{-}$ & 45 \\
\hline 3. & IX- $^{3}$ & 45 \\
\hline 4. & IX- $^{-}$ & 45 \\
\hline 5. & IX- $^{5}$ & 46 \\
\hline 6. & IX- $^{-}$ & 46 \\
\hline 7. & IX- $^{-}$ & 46 \\
\hline 8. & IX- $^{-}$ & 46 \\
\hline 10. & IX- $^{-}$ & 46 \\
\hline & Jumlah & 405 \\
\hline
\end{tabular}




\section{seluruh siswa}

\section{Sampel}

Sampel adalah sebahagian atau wakil populasi yang diteliti, sampel penelitian haruslah benar-benar mewakili seluruh populasi, atau sampel juga harus memberikan keterangan yang diperlukan agar lebih dapat dipercaya.

Dalam penelitian ini tidaklah seharusnya keseluruhan populasi diteliti, dan juga mengingat banyaknya hal yang harus dipertimbangkan di dalam penelitian ini yakni tenaga, waktu yang lama, dan lainlain.

Arikunto mengemukakan pendapat "apa bila jumlah subjek kurang dari 100 lebih baik diambil semua sehingga penelitiannya merupakan penelitian populasi. Selanjutnya jika jumlah subjeknya lebih dari 100 maka diambil antara 10\% $15 \%$ atau lebih. Maka dalam hal ini penulis menentukan sampel penelitian ini yakni sebanyak 40 siswa dari jumlah populasi secara keseluruhan".

Berdasarkan pendapat di atas, maka yang menjadi sampel hanya satu kelas IX-1 yang berjumlah 40 orang. Pemilihan sampel dilakukan dengan cara memilih langsung kelas yang ingin diteliti, sehingga diperoleh jumlah yang dibutuhkan sebagai respondent.

Tabel .Sampel penelitian

\begin{tabular}{lcc}
\hline No & Kelas & Jumlah \\
\hline 1. & IX-1 & 40 Siswa \\
\hline
\end{tabular}

\section{Teknik Pengumpula Data}

Untuk memperoleh data yang lebih optimal dan akurat, penelitian menggunakan alat bantu, Alat bantu dalam penelitian ini menggunakan angket sebagai instrument penelitiannya. Pemberian angket untuk mengetahui perkembangan komunikasi interpersonal pada siswa.

\section{Teknik Analisis Data}

1. Uji normalitas.

Pengujian normalitas dilakukan untuk mengetahui normal tidaknya suatu distribusi data. Hal ini penting di ketahui berkaitan dengan ketetapan pemilihan uji statistik yang akan di gunakan. Uji parametik misalnya, mengisyaratkan data harus berdistribusi normal. Apabila distribusi data tidak normal maka di sarankan untuk menggunakan uji non paparametrik.

Pengujian normalitas ini harus di lakukan apabila belum ada teori yang menyatakan bahwa variabel yang di teliti adalah normal. Dengan kata lain, apabila ada teori yang menyatakan bahwa suatu variabel yang sedang di teliti adalah normal, maka tidak di perlukan lagi pengujian normalitas data.

Setelah data penelitian ini terkumpul yaitu hasil test yang diberikan maka data tersebut akan dianalisis dengan langkahlangkah sebagai berikut:

a) Menentukan mean

Dengan menggunakan rumus:

$$
\begin{aligned}
& \bar{X}=\frac{\sum X_{i}}{n} \\
& \bar{Y}=\frac{\sum Y_{i}}{n}
\end{aligned}
$$

b) Standard deviasi

$$
\begin{aligned}
& S_{x}=\sqrt{\frac{n \sum X^{2}-\left(\sum X\right)^{2}}{n(n-1)}} \\
& S_{y}=\sqrt{\frac{n \sum Y^{2}-\left(\sum Y\right)^{2}}{n(n-1)}}
\end{aligned}
$$

c) Uji normalitas

Uji normalitas mengikuti prosedur yang dalam Sudjana adalah: 
1. Pengamatan $X_{1}, X_{2}, \ldots \ldots X_{n}$ dijadikan angka baku $\mathrm{Z}_{1}, \mathrm{Z}_{2}$, $\ldots \ldots \mathrm{Z}_{\mathrm{n}}$ dengan menggunakan rumus:

$Z_{1}=\frac{X_{i}-\bar{X}}{S}$

$(\bar{X} \quad$ dan $\quad \mathrm{S}$ masing-masing merupakan rata-rata dan simpangan baku dari sampel)

2. Untuk itu tiap angka baku ini dan menggunakan daftar distribusi moral baku, kemudian dihitung peluang $\mathrm{F}\left(\mathrm{Z}_{\mathrm{i}}\right)=\mathrm{P}(\mathrm{Z} \leq$ $\mathrm{Z}_{\mathrm{i}}$ )

3. Selanjutnya hitung proporsi $Z_{1}$, $\mathrm{Z}_{2}, \ldots \ldots \mathrm{Z}_{\mathrm{n}}$ yang lebih kecil atau sama dengan $Z_{1}$ jika proporsi ini berdasarkan pada $\mathrm{S}\left(\mathrm{Z}_{\mathrm{i}}\right)$ maka: $\mathrm{SZ}_{\mathrm{i}}=$

$\frac{\text { Banyaknya } \mathrm{Z}_{1}, \mathrm{Z}_{2}, \ldots, \mathrm{Z}_{\mathrm{n}} \text { yang } \leq \mathrm{Z}_{\mathrm{i}}}{\mathrm{n}}$

4. Hitung selisih $\mathrm{F}\left(\mathrm{Z}_{\mathrm{i}}\right)-\mathrm{S}\left(\mathrm{Z}_{\mathrm{i}}\right)$ kemudian tentukan harga mutlaknya.

Ambil harga yang besar diantara harga mutlak tersebut. Sebut harga mutlak sebesar ini $\mathrm{L}_{0}$ kemudian $\mathrm{L}_{\mathrm{o}}$ ini dibandingkan dengan harga $\mathrm{L}_{\text {label }}$ yang diambil dalam nilai kritik untuk uji Liliefors dengan taraf nyata $\alpha=$ 0,05 . Kriteria pengujian adalah diterima data berdistribusi normal bila $\mathrm{L}_{\mathrm{o}}<\mathrm{L}_{\text {label }}$ dalam hal lainnya hipotesis ditolak.

\section{Uji homogenitas data.}

Uji homogenitas yang akan di bahas dalam tulisan ini adalah uji homogenitas variansi dan uji burlett. Uji homogenitas di lakukan untuk mengetahui apakah data dalam variabel $\mathrm{X}$ dan $\mathrm{Y}$ bersifat homogen atau tidak. Untuk menguji apakah kedua kelompok homogeny, akan diuji hipotesis sebagai berikut :

$$
\text { Ho : } \alpha 1^{2}=\alpha 2^{2}
$$

Ho : $\alpha 1^{2} \neq \alpha 2^{2}$

Rumus statistic yang digunakan adalah :

Fhitung $=\frac{S_{1}^{2}}{S_{2}^{2}}$

Kriteria Pengujian

Terima Ho Jika Fhitung $<$ Ftabel

3. Uji asosiatif

a. Untuk mengetahui apakah ada hubungan antar variabel bebas (X) dengan variabel terikat (Y) dalam mebuktikan benar atau tidaknya hipotesis yang di ajukan, maka digunakan rumus koefesien korelasi product moment yaitu :

$$
r_{x y}=\frac{N \sum X Y-\left(\sum X\right)\left(\sum Y\right)}{\sqrt{\left\{N \sum X^{2}-\left(\sum X\right)^{2},\left\{N . Y^{2}-\left(\sum Y\right)^{2}\right\}\right.}}
$$

Keterangan :

$=$ Koefisien korelasi antara variabel $\mathrm{X}$ (pengaruh $\mathrm{b}$ kelompok) dengan variabel Y (peningkatan komun siswa)

$\sum X Y=$ Jumlah hasil perkalian antara variabel $\mathrm{X}$ dan Y

$\sum X \quad=$ Jumlah skor keseluruhan subjek variabel bebas $\mathrm{X}$

$\sum Y \quad=$ Jumlah skor keseluruhan subjek variabel Y

$\sum X^{2}=$ Jumlah kuadrat skor variabel $\mathrm{X}$

$\sum Y^{2}=$ Jumlah kuadrat skor variabel $Y$

$N$

$=$ Jumlah subjek

b. Untuk menguji taraf signifikasi rumus diatas, maka digunakan rumus uji t 
yaitu: $\quad t=\frac{r \sqrt{N-2}}{\sqrt{1-r^{2}}}$

Keterangan :

$\mathrm{t}=$ Hasil dari $\mathrm{t}^{\text {table }}$

$\mathrm{r}=$ Jumlah dari korelasi

$\mathrm{N}=$ Jumlah sampel

R2 = Hasil korelasi

\begin{tabular}{|c|c|c|c|c|c|c|c|c|c|c|c|c|c|}
\hline & 1 & 2 & 3 & 4 & 5 & & 7 & & & 10 & $\bar{Y}$ & & \\
\hline 1 & 4 & 2 & 3 & 4 & 3 & 4 & 4 & 3 & 4 & 2 & 33 & 82.5 & 6806.25 \\
\hline 2 & 3 & 4 & 4 & 3 & 2 & 4 & 4 & 2 & 3 & 4 & 33 & 82.5 & 6806.25 \\
\hline 3 & 4 & 3 & 2 & 2 & 4 & 3 & 3 & 4 & 4 & 3 & 32 & 80 & 6400 \\
\hline 4 & 3 & 4 & 4 & 3 & 3 & 4 & 4 & 3 & 3 & 4 & 35 & 87.5 & 7656.25 \\
\hline 5 & 2 & 3 & 2 & 3 & 1 & 3 & 3 & 4 & 4 & 1 & 26 & 65 & 4225 \\
\hline 6 & 3 & 4 & 2 & 4 & 3 & 4 & 4 & 3 & 3 & 4 & 34 & 85 & 7225 \\
\hline 7 & 4 & 3 & 4 & 3 & 4 & 3 & 3 & 4 & 4 & 3 & 35 & 87.5 & 7656.25 \\
\hline 8 & 2 & 3 & 3 & 4 & 3 & 4 & 4 & 3 & 2 & 3 & 31 & 77.5 & 6006.25 \\
\hline 9 & 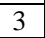 & 2 & 4 & 4 & 2 & 3 & 2 & 3 & 3 & 2 & 28 & 70 & 4900 \\
\hline 10 & 2 & 4 & 3 & 3 & 4 & 4 & 3 & 2 & 3 & 4 & 32 & 80 & 6400 \\
\hline 11 & 1 & 3 & 4 & 4 & 3 & 3 & 4 & & 3 & 4 & 29 & 72.5 & 5256.25 \\
\hline 12 & 3 & 4 & 3 & 3 & 1 & 4 & 4 & 2 & 4 & 3 & 31 & 77.5 & 6006.25 \\
\hline 13 & 4 & 3 & 4 & 4 & 3 & 3 & 3 & 4 & 3 & 4 & 35 & 87.5 & 7656.25 \\
\hline 14 & 1 & 3 & 2 & 3 & 2 & 4 & 4 & 3 & 4 & 3 & 29 & 72.5 & 5256.25 \\
\hline 15 & 2 & 4 & 1 & 4 & 3 & 2 & 2 & 1 & 2 & 3 & 24 & 60 & 3600 \\
\hline 16 & 4 & 3 & 2 & 3 & 2 & 4 & 4 & 2 & 3 & 2 & 29 & 72.5 & 5256.25 \\
\hline 17 & 3 & 4 & 2 & 2 & 3 & 2 & 4 & 4 & 2 & 3 & 29 & 72.5 & 5256.25 \\
\hline 18 & 4 & 3 & 4 & 3 & 2 & 3 & 2 & 4 & 4 & 2 & 31 & 77.5 & 6006.25 \\
\hline 19 & 2 & 3 & 3 & 3 & 3 & 2 & 4 & 3 & 3 & 4 & 30 & 75 & 5625 \\
\hline 20 & 3 & 2 & 4 & 4 & 1 & 3 & 3 & 4 & 4 & 3 & 31 & 77.5 & 6006.25 \\
\hline 21 & 1 & 3 & 2 & 1 & 4 & 1 & 4 & 3 & 3 & 2 & 24 & 60 & 3600 \\
\hline 22 & 3 & 2 & 4 & 3 & 3 & 3 & 2 & 4 & 4 & 27 & 30 & 75 & 5625 \\
\hline 23 & 2 & 3 & 3 & 1 & 4 & 2 & 4 & 3 & 3 & 1 & 26 & 65 & 4225 \\
\hline 24 & 3 & 3 & 4 & 3 & 3 & 3 & 3 & 4 & 4 & 3 & 33 & 82.5 & 6806.25 \\
\hline 25 & 4 & 4 & 3 & 4 & 4 & 3 & 4 & 3 & 3 & 4 & 36 & 90 & 8100 \\
\hline 26 & 3 & 4 & 3 & 2 & 3 & 4 & 3 & 4 & 4 & 3 & 33 & 82.5 & 6806.25 \\
\hline 27 & 4 & 3 & 4 & 2 & 4 & 3 & 4 & 3 & 3 & 4 & 34 & 85 & 7225 \\
\hline 28 & 2 & 4 & 3 & 4 & 3 & 4 & 3 & 4 & 4 & 3 & 34 & 85 & 7225 \\
\hline 29 & 3 & 4 & 2 & 3 & 4 & 3 & 2 & 3 & 2 & 3 & 29 & 72.5 & 5256.25 \\
\hline 30 & 3 & 2 & 4 & 4 & 2 & 3 & 2 & 4 & 4 & 2 & 30 & 75 & 5625 \\
\hline 31 & 2 & 4 & 3 & 3 & 4 & 2 & 4 & 3 & 3 & 4 & 32 & 80 & 6400 \\
\hline 32 & 1 & 3 & 4 & 4 & 3 & 3 & 3 & 4 & 4 & 3 & 32 & 80 & 6400 \\
\hline 33 & 3 & 4 & 3 & 3 & 1 & 3 & 4 & 3 & 3 & 4 & 31 & 77.5 & 6006.25 \\
\hline 34 & 3 & 2 & 4 & 3 & 2 & 4 & 3 & 4 & 4 & 3 & 32 & 80 & 6400 \\
\hline 35 & 2 & 4 & 3 & 2 & 3 & 3 & 2 & 4 & 4 & 2 & 29 & 72.5 & 5256.25 \\
\hline 36 & 3 & 3 & 4 & 3 & 3 & 2 & 4 & 4 & 2 & 3 & 31 & 77.5 & 6006.25 \\
\hline 37 & 3 & 4 & 3 & 3 & 2 & 4 & 3 & 3 & 4 & 4 & 33 & 82.5 & 6806.25 \\
\hline 38 & 4 & 3 & 4 & 4 & 3 & 3 & 4 & 4 & 3 & 3 & 35 & 87.5 & 7656.25 \\
\hline 39 & 3 & 4 & 3 & 3 & 3 & 4 & 3 & 3 & 4 & 4 & 34 & 85 & 7225 \\
\hline 40 & 4 & 3 & 4 & 4 & 4 & 3 & 4 & & 3 & 3 & 36 & 90 & 8100 \\
\hline & & & & & & & & & & & & 3127.5 & 246756.3 \\
\hline
\end{tabular}

Dari hasil perhitungan di atas dapat diperoleh nilai rata-rata siswa dengan menggunakan rumus berikut :

$$
\begin{aligned}
& \bar{y}=\frac{\sum y}{n} \\
& \bar{y}=\frac{3127,5}{40} \\
& \bar{y}=78,18
\end{aligned}
$$

Dengan standar deviasi

$$
\begin{aligned}
& S_{y}=\sqrt{\frac{\left.n \sum y^{2}\right)-\left(\sum y\right)^{2}}{n * n-1}} \\
& S_{y}=\sqrt{\frac{40 x 246756,5)-9781256}{40 *(40-1)}} \\
& S_{y}=\sqrt{\frac{9870250-9781256}{1560}} \\
& S_{y}=\sqrt{57,04} \\
& S_{y}=7,55
\end{aligned}
$$


Dari data yang diperoleh di atas, maka didapat nilai rata-rata komunikasi interpersonal siswa sebesar 78,18 dengan standart deviasi sebesar 7,5. Selanjutnya dilakukan uji normalitas yang dapat dilihat dari tabel berikut ini :

Tabel. Uji normalitas variabel y

\begin{tabular}{|c|c|c|c|c|c|c|}
\hline $\mathbf{Y i}$ & $\mathbf{f i}$ & $\mathbf{f k}$ & $\mathbf{Z i}$ & $\mathbf{F}(\mathbf{Z 1})$ & $\mathbf{S}(\mathbf{Z 1})$ & $\begin{array}{c}\mathbf{F}(\mathbf{Z 1})- \\
\mathbf{S}(\mathbf{Z 1})\end{array}$ \\
\hline 60 & 2 & 2 & -2.41 & 0.04 & 0.05 & $(0.01)$ \\
\hline 65 & 2 & 4 & -1.75 & 0.19 & 0.1 & 0.09 \\
\hline 70 & 1 & 5 & -1.08 & 0.113 & 0.125 & $(0.01)$ \\
\hline 72.5 & 6 & 11 & -0.75 & 0.124 & 0.275 & $(0.15)$ \\
\hline 75 & 3 & 14 & -0.42 & 0.293 & 0.35 & $(0.06)$ \\
\hline 77.5 & 6 & 20 & -0.09 & 0.33 & 0.5 & $(0.17)$ \\
\hline 80 & 5 & 25 & 0.24 & 0.543 & 0.625 & $(0.08)$ \\
\hline 82.5 & 5 & 30 & 0.57 & 0.71 & 0.75 & $(0.04)$ \\
\hline 85 & 4 & 34 & 0.90 & 0.801 & 0.85 & $(0.05)$ \\
\hline 87.5 & 4 & 38 & 1.23 & 0.81 & 0.95 & $(0.14)$ \\
\hline 90 & 2 & 40 & 1.56 & 0.9883 & 1 & $(0.01)$ \\
\hline
\end{tabular}

Dari hasil yang diperoleh diatas maka Lo $=0,17$ dan untuk $\mathrm{L}_{\text {tabel }}=\frac{0,886}{\sqrt{n}}$ sehingga untuk $\mathrm{L}_{\text {tabel }}=0,18$. Kriteria pengujian adalah, jika Lo $<\mathrm{L}_{\text {tabel }}$ maka data berdistribusi normal, maka $0,16<0,18$ sehingga dapat dikatakan data berdistribusi normal

Untuk mengetahui data yang diperoleh bersifat homogen atau tidak, maka dilakukan uji homogenitas dengan rumus berikut ini:

$$
\begin{aligned}
& F=\frac{S_{1}^{2}}{S_{2}^{2}} \\
& F=\frac{8,5^{2}}{7,5^{2}} \\
& F=\frac{72,25}{56,25} \\
& F=1,28
\end{aligned}
$$

Dari data tersebut diperoleh nilai $\mathrm{F}_{\text {Hitung }}$ $=1,28$ dengan $F_{\text {tabel }}=2,08$, dengan kriteria $F_{\text {hitung }}<\mathrm{F}_{\text {tabel }}$ berarti data homogeny, maka dengan kriteria tersebut data yang diperoleh adalah homogen.

\section{Pembahasan Penelitian}

Pada penelitian ini diperoleh beberapa Hasil penelitian yaitu:
1. Pada tes komunikasi interpersonal diperoleh nilai rata-rata siswa sebesar 61,8 dan untuk tes bimbingan kelompok diperoleh nilai rata-rata sebesar 78,18.

2. Untuk standart deviasi variabel $\mathrm{x}$ diperoleh nilai 8,5 dan untuk standar deviasi variabel y diperoleh nilai 7,5.

3. Perolehan nilai uji normalitas variabel $x$ dan variabel y menyatakan bahwa data yang diteliti bersifat normal

4. Perolehan data untuk homegenitas data menunjukkan bahwa data yang diteliti bersifat homogen.

5. Untuk hasil $\mathrm{r}_{\text {hitung }}=0,35$ dengan menggunakan taraf 5\% maka diperoleh nilai $r_{\text {tabel }}=0,30$ dengan sampel 40 orang siswa. Kriteria pengujian adalah jika $\mathrm{r}_{\text {hitung }}>\mathrm{r}_{\text {tabel }}$ maka hipotesis diterima, berdasarkan kriteria tersebut, 0,35>0,30 sehingga ada pengaruh bimbingan kelompok terhadap komunikasi interpersonal siswa kelas IX SMP Negeri 3 Binjai Tahun Pelajaran 2017/2018.

6. Nilai $t_{\text {hitung }}=2,32$ dengan taraf 0,05 maka diperoleh nilai $t_{\text {tabel }}=2,02$ dengan kriteria pengujia terima hipotesis jika $t_{\text {hitung }}>t_{\text {tabel }}$. Maka 2,32> 2,02 sehingga dapat disimpulkan bahwa ada pengaruh yang signifikan antara penggunaan bimbingan kelompok terhadap peningkatan komunikasi interpersonal siswa kelas IX SMP Negeri 3 Binjai tahun Pelajaran 2017/2018

\section{PENUTUP}

\section{Kesimpulan}

Dari hasil dan analisis data diperoleh beberapa kesimpulan yaitu :

1. Pada tes komunikasi interpersonal diperoleh nilai rata-rata siswa sebesar 61,8 dan untuk tes bimbingan kelompok 
diperoleh nilai rata-rata sebesar 78,18. Untuk standart deviasi variabel $\mathrm{x}$ diperoleh nilai 8,5 dan untuk standar deviasi variabel y diperoleh nilai 7,5.

2. Perolehan nilai uji normalitas variabel $x$ dan variabel y menyatakan bahwa data yang diteliti bersifat normal dan perolehan data untuk homegenitas data menunjukkan bahwa data yang diteliti bersifat homogen.

3. Untuk hasil $r_{\text {hitung }}=0,35$ dengan menggunakan taraf 5\% maka diperoleh nilai $r_{\text {tabel }}=0,30$ dengan sampel 40 orang siswa. Kriteria pengujian adalah jika $r_{\text {hitung }}>r_{\text {tabel }}$ maka hipotesis diterima, berdasarkan kriteria tersebut, $0,35>0,30$ sehingga ada pengaruh bimbingan kelompok terhadap komunikasi interpersonal siswa kelas IX SMP Negeri 3 Binjai Tahun Pelajaran 2017/2018. Dengan uji signifikan dapat disimpulkan bahwa ada pengaruh yang signifikan antara penggunaan bimbingan kelompok terhadap peningkatan komunikasi interpersonal siswa kelas IX SMP Negeri 3 Binjai tahun Pelajaran 2017/2018.

\section{Saran}

Sejalan dengan kesimpulan yang telah dibuat, maka berikut ini dapat diberikan beberapa saran, antara lain :

1. Saran kepada sekolah

Melihat kondisi pelayanan bimbingan kelompok yang dinilai sangat baik, maka disarankan kepada pihak sekolah agar terus berupaya mempertahankan mutu pelayanan bimbingan kelompok yang selama ini berlansung di sekolah. Diharapkan dengan nilai baiknya pelaksanaan bimbingan kelompok ini, maka para siswa tetap menggunakan jasa layanan tersebut untuk kepentingan siswa.

2. Saran kepada subjek penelitian Kepada subjek penelitian diharapkan agar selalu menggunakan jasa pelayanan bimbingan konseling yang disediakan oleh pihak sekolah. Hendaknya para siswa menjadikan layanan dan konseling di sekolah sebagai pengganti orang tua. Dengan demikian para siswa dapat berkomunikasi dengan baik kepada siapa saja.

3. Saran kepada peneliti berikutnya Menyadari bahwa penelitian ini tidaklah sempurna, maka disarankan kepada peneliti selanjutnya yang ingin melanjutkan penelitian ini untuk mengkaji faktor-faktor lain yang berhubungan dengan perubahan prilaku, misalnya faktor kepribadian individu. Diharapkan dengan adanya penelitian lanjutan ini, hasil penelitian menjadi lebih lengkap.

\section{DAFTAR PUSTAKA}

Arikunto, Suharsini.Prosedur Penelitian Suatu Pendekatan Praktek Jakarta : Rineka Cipta.2006

Gadza, Materi Pendididikan dan Latihan Profesi Guru Jakarta : PLPG.2010

Hidayah Rifa Bimbingan Konseling Islami. Jakarta : Bumi Aksara.2009. http://warnaawarnii.blogspot.com/2013/01/pengertiantujuan-bimbingan.html

http:// jurnalsdm.blogspot.com/2010/01/komunikasi interpersonal-defenisi.html 
Jalaluddin Rakhmat, Psikologi Komunikasi. Bandung : Remaja Rosdakarya. 2005

Lubis Lahmuddin. Landasan Formal Bimbingan Konseling di Indonesia. Bandung : Citapustaka Media Perintis.2011

M Bakar Abu. Luddin, dasar-dasar konseling tinjauan teori dan praktik Bandung : Citapustaka Media Perintis.2010

Riduan. Belajar Muda Penelitian. Bandung : Alpabet, 2010

Sugiyo, Komunikasi Antar pribadi, Semarang : UNNES Press, 2005

Sudjana, Prosedur Penelitian. Jakarta : Rineka Cipta,2002

Undang-undang, Sistem Pendidikan. Jakarta : Sandrojaya 2010

Prayitno, Dasar-Dasar Bimbingan dan Konseling. Jakarta : Rineka Cipta. 2007

Wiryanto, Program Ilmu Komunikasi, Jakarta : Grasindo, 2005

Wibowo, Mungin Edi, Konseling Kelompok Perkembangan. Semarang : UNNES Press. 2005

Warsito Herman. Pengantar Metodologi Penelitian. Jakarta:PT Gramedia,2009 